\title{
Biogas Purification by Alkali-based Column Washing Extracted from Wood Ash and Banana Stalks
}

\author{
Paul Nestor Djomou Djonga ${ }^{1,}$, , Jeanne Atchana ${ }^{1}$, Alexis Nankap ${ }^{2}$, Fabrice Kwefeu Mbakop ${ }^{2,3}$, \\ Raphael Djackba ${ }^{1}$, Abel Tame ${ }^{4}$ \\ ${ }^{1}$ Department of Chemistry, Faculty of Science, University of Maroua, Maroua, Cameroon \\ ${ }^{2}$ Department of Economics, University Institute of Sciences, Technologies and Ethics, Yaounde, Cameroon \\ ${ }^{3}$ Department of Renewable Energy, National Advanced Polytechnic School, University of Maroua, Maroua, Cameroon \\ ${ }^{4}$ Department of Inorganic Chemistry, University of Yaounde I, Yaounde, Cameroon
}

\section{Email address:}

djomoupaul@gmail.com (P. N. D. Djonga)

${ }^{*}$ Corresponding author

\section{To cite this article:}

Paul Nestor Djomou Djonga, Jeanne Atchana, Alexis Nankap, Fabrice Kwefeu Mbakop, Raphael Djackba, Abel Tame. Biogas Purification by Alkali-based Column Washing Extracted from Wood Ash and Banana Stalks. Science Journal of Energy Engineering.

Vol. 8, No. 1, 2020, pp. 6-14. doi: 10.11648/j.sjee.20200801.12

Received: April 16, 2020; Accepted: May 21, 2020; Published: June 4, 2020

\begin{abstract}
The production of biogas as an energy source from organic waste is a viable option for waste recovery and reduction of greenhouse gases. Before any use of biogas, however, hydrogen sulfide and carbon must be removed to preserve consumer health and the life of the equipment. In this work, we were talking about purifying the biogas by washing on a column with an alkali solution produced from wood ash and ash from the wood stalk. To do this, a functional analysis of the purification system was made. After characterization of the samples, the alkalis were extracted, which were subsequently characterized. The next step was to carry out biogas purification tests from the alkali crystals. The extraction yield of alkali is $7 \%$ for the ash of meat grillers and $12 \%$ with the ash of banana stalk. The biogas was washed with an alkali concentration of $0.1 \mathrm{~g} / \mathrm{ml}$. The optimal residence time offering the best washing is $23 \mathrm{~min}$ for $\mathrm{CO}_{2}$ and $32 \mathrm{~min}$ for $\mathrm{H}_{2} \mathrm{~S}$. This study found that the alkali on the banana boom is better. During the washing test, a $\mathrm{CO}_{2}$ absorption capacity of $4.52 \mathrm{~g} / \mathrm{ml}$ of the alkali solution and $20.45 \mathrm{ppm} / \mathrm{ml}$ of $\mathrm{H}_{2} \mathrm{~S}$ was recorded. By making an extrapolation It follows that for these quantities of $\mathrm{CO}_{2}$ and $\mathrm{H}_{2} \mathrm{~S}$ absorbed per milliliter, during a domestic installation, for a volume of alkali of $1000 \mathrm{ml}$, we will have a volume of $\mathrm{CO}_{2}$ of $2,53 \mathrm{~m}^{3}$ and a biogas volume of $6.33 \mathrm{~m}^{3}$.
\end{abstract}

Keywords: Alkali, Banana Stalks, Biogas, Purification, Wood Ash

\section{Introduction}

The development potential of human societies is conditioned by access to natural resources in general and in particular to energy resources since the advent of the industrial age. However, the coming decades will be marked by a scarcity of these resources which will have a considerable impact on our means of production and our way of life, as much from the energy point of view as from the point of view of the raw materials for the manufacture of the objects of our everyday life. Moreover, this decline in fossil resources coincides with an increase in the demand for world population growth and the economic development of emerging countries [1-3].

In this context, it is essential to seek new sources of energy and materials before it is too late. This challenge is that of all the countries of the world and particular of Cameroon. In this country, for example, total energy consumption was estimated at $8521 \mathrm{Ktep}(1$ toe $=11,628 \mathrm{KWh})$ in 2010 [4-8], of which only $21 \%$ came from fossil fuels. As for traditional energies, especially those of biomass (wood, charcoal, agricultural residues), they represent $65 \%$ of energy consumption. This results in an annual loss of $3.4 \%$ of the national forest cover [2, 9-12]. In recent years, great attention has been paid to the use of biomass. Defined as the biodegradable fraction of all organic matter (waste or 
products) from agriculture, forestry or municipal and industrial waste, it is a source of carbon integrated into a short cycle. If the production of these resources is as fast as their use, they are considers renewable. Anaerobic digestion is a proven process Volta who introduces him into the scientific community in 1776) [13] whose achievements in large scale are already numerous.

This process is the controlled implementation of the natural process of degradation of organic matter in the absence of oxygen. It produces biogas, which is a flammable mixture composed mainly of methane and carbon dioxide that can be used for many applications similar to those of natural gas [14]. In this context, it is essential to seek new sources of energy and materials before it is too late. This challenge is that of all the countries of the world and particular of Cameroon. In this country, for example, total energy consumption was estimated at 8521 ktoe ( 1 toe $=11,628 \mathrm{KWh}$ ) in 2010 [4-8], of which only $21 \%$ came from fossil fuels. As for traditional energies, especially those of biomass (wood, charcoal, agricultural residues), they represent $65 \%$ of energy consumption. This results in an annual loss of $3.4 \%$ of the national forest cover [2, 9-12].

In recent years, great attention has been paid to the use of biomass. Defined as the biodegradable fraction of all organic matter (waste or products) from agriculture, forestry or municipal and industrial waste, it is a source of carbon integrated into a short cycle. If the production of these resources is as fast as their use, they are considers renewable. Anaerobic digestion is a proven process Volta who introduces him into the scientific community in 1776) [13] whose achievements in large scale are already numerous. This process is the controlled implementation of the natural process of degradation of organic matter in the absence of oxygen. It produces biogas, which is a flammable mixture composed mainly of methane and carbon dioxide that can be used for many applications similar to those of natural gas [14].

However, the production of this form of energy does not remain without danger vis-à-vis the population and the environment. It will be necessary to eliminate this danger in order to be able to exploit it easily and without compromise. Biogas purification and bio-methane production are today leading technologies in the field of gas separation. Several processes, marketed, allow producing bio-methane of good quality to make bio-fuel or to inject into the natural gas network. They have demonstrated their feasibility both technically and economically. However, active research is underway to optimize existing techniques or even to open up new applications in the field of biogas purification [14-17]. Each technology has specific advantages and disadvantages.

As part of our work, we have chosen as a general goal to purify biogas by column washing. It is more specifically about:

a) The extraction of alkali from the ashes of wood and ash from banana stems and their characterization;

b) The purification of biogas.

\section{Material and Methods}

\subsection{Plastic Material}

The plant material used to carry out this work consists of banana stalks (Musa Balbissiana) taken from the banana market at the Ngaoundéré freight station in May.

\subsection{Ashes}

The ashes used in this study are from the combustion of wood. These ashes were collected from meat grillers located $50 \mathrm{~m}$ from the main entrance of the University of Ngaoundere.

\subsection{Biogas}

This is the residue of bio-methanisation taken from the biogas production site at Bini in the Ngaoundéré District III. This biogas is produced in a 250 liter barrel digester.

\subsection{Biogas Purification Unit}

The biogas decarbonation and desulphurization device used in this work is a laboratory scale pilot unit. This unit is mounted on the biogas production site in Bini Dang. Figure 1 below shows an overview of the device. The device is mounted on a $125 \times 125 \mathrm{~mm}$ plywood. This device is equipped with a plastic tube (PVC) one meter long and 26 $\mathrm{mm}$ in diameter to be used for absorption tests. Everything is placed at atmospheric pressure.

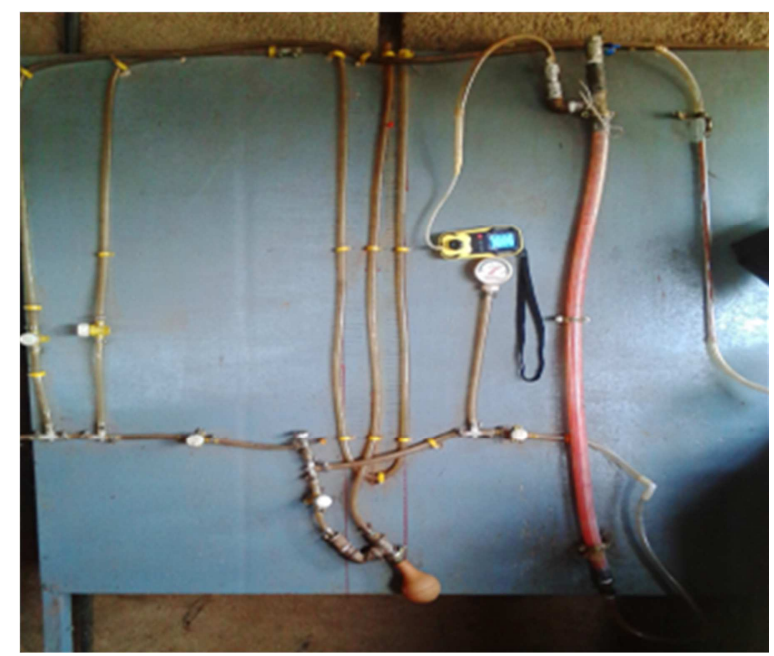

Figure 1. Experimental device for purification of biogas.

This device is equipped with three valves. The first valve allows the entry of water into the column. The second serves to introduce the unpurified biogas. Finally, the third is used to extract the purified biogas. A column graduated in centimeters makes it possible to measure the flow of the biogas at the entrance of the column.

\subsection{The Gas Analyzer}

Figure 2 below shows the SAZQ model gas analyzer that we use to simultaneously detect methane $\left(\mathrm{CH}_{4}\right)$, carbon 
dioxide $\left(\mathrm{CO}_{2}\right)$ and hydrogen sulphide $\left(\mathrm{H}_{2} \mathrm{~S}\right)$.

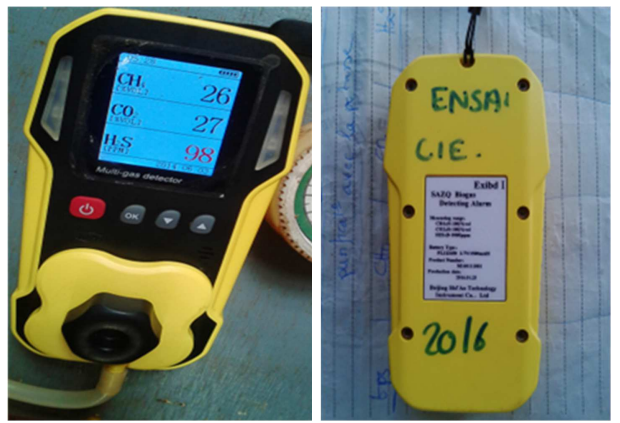

Figure 2. Biogas measuring device.

\section{Method}

The work consists of a functional analysis, followed by a sampling of the basic raw materials. This material will then be characterized in order to assess the content of dry matter, ash content and organic matter. Thereafter, we will have in the production of ash by calcination in the oven at $550^{\circ} \mathrm{C}$, then the extraction and purification of alkalis will be carried out and chemical tests such as alkalinity and measurement of $\mathrm{Ph}$.

\subsection{Characterization of Banana Stems Samples}

The banana stem samples are cut into small pieces (Figure 3). Two drying temperatures are tested. The first is to dry at $105^{\circ} \mathrm{C}$ in a PROLABO oven and the second drying is performed at room temperature (sun).

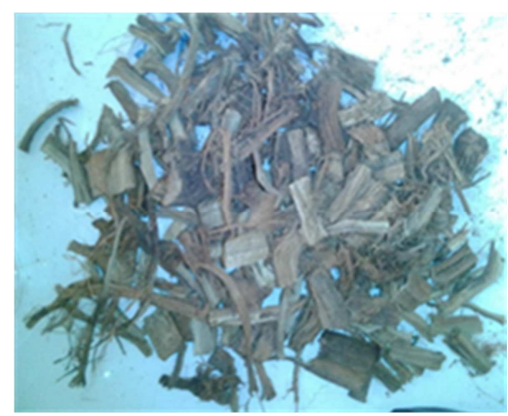

Figure 3. Sun drying.

The banana stalks are characterized by the determination of their content of dry matter, organic matter and ash.

\subsubsection{Dry Matter Content}

The dry matter is determined using a BINDER oven heated to $105^{\circ} \mathrm{C}$. It is the dry residue obtained by the application of the method described below. This material is expressed in percentage and mass. In a crucible of mass $t, 30$ $\mathrm{g}$ of sample are weighed $\left(m_{0}\right)$ and dried in an oven at $105^{\circ} \mathrm{C}$ for 24 hours. The test portions are cooled in desiccators for one to three hours of time. The crucible containing the sample is weighed and the mass $\mathrm{ml}$ is obtained. The dry matter content expressed as a percentage is determined by the following expression.

$$
100-\left(\left[\frac{m_{0}-m_{1}}{m_{0}-t}\right] \times 100\right)=\% \text { of dry matter }
$$

Where $t=$ weight of the crucible; $m_{0}=($ crucible + sample $)$ before baking; $m_{l}=($ crucible + sample $)$ after steaming.

\subsubsection{Ash Content}

In this study, 5 to $10 \mathrm{~g}$ of oven-dried sample is dried to constant mass. The sample is then weighed and the mass $\mathrm{M}_{1}$ is obtained. It is then calcined in an oven at $600^{\circ} \mathrm{C}$. for 24 hours and finally the material obtained $\left(\mathrm{M}_{2}\right)$ is weighed. The expression of the ash content is given by:

$$
\text { Ash content }=\frac{M_{2}}{M_{1}}
$$

$M_{1}$ : sample mass before oven; $M_{2}$ : sample mass after oven.

\subsubsection{Organic Material}

The most common method for determining organic matter content is loss on ignition. $25 \mathrm{~g}$ of sample dried at $105^{\circ} \mathrm{C}$. (Ms) is incinerated at $550^{\circ} \mathrm{C}$. in a muffle furnace until the complete disappearance of the carbonaceous particles. After two hours, the capsules are cooled in a desiccator and weighed (Mc). The organic matter content expressed as a percentage is determined by the following expression.

$$
\% M . O=\frac{\left[M_{S}-M_{C}\right]}{M_{S}} \times 100
$$

With: \% $M$. $O=$ percentage of organic matter in the dry sample; $M_{S}=$ sample mass after oven drying at $105^{\circ} \mathrm{C}$; $M_{C}=$ mass of the sample after calcination.

\subsection{Production and Characterization of Ashes}

Banana stem ash is obtained by calcination of dried stalks. The samples are calcined at $550^{\circ} \mathrm{C}$. using the NABERTHER brand oven [17-19].

\subsubsection{Traction and Purification of Alkali}

The procedure for extracting alkali consists of dissolving the ashes of banana stalks and those of wood in distilled water. Samples of banana stem ash and wood are sifted to remove coarse particles. The sieve is dissolved in distilled water. The suspension obtained is agitated manually until complete dissolution of the minerals contained in the sieves. The suspension is filtered and left standing until settling. Two additional extraction operations are performed on the extraction residues. The supernatants are recovered and concentrated in a PROLABO oven at $105^{\circ} \mathrm{C}$. After evaporation of the water, the alkali crystals obtained are weighed and the extraction yield determined.

\subsubsection{Extraction Efficiency}

The extraction yield of the crystals is determined according to the following formula:

$$
\text { Efficiency }=\frac{W_{A}}{W_{C}}
$$

With $W_{A}$ : weight of the extracted alkali and $W_{C}$ : the initial ash weight. 


\subsection{Characterization of the Crystals Obtained}

\subsubsection{Ph Measurement}

The $\mathrm{pH}$ of the crystals is determined from a $\mathrm{pH}$ meter. It allows us to know the basicity of the reagent.

\subsubsection{Determination of the Alkalinity of the Reagent}

TA-TAC.

The alkalinity of water corresponds to the presence within it of hydroxides, carbonates, bicarbonates, alkalis and alkaline earths.

The alkalimetric titer is the volume of acid (expressed in $\mathrm{ml}$ ) at $0.1 \mathrm{~mol} . \mathrm{L}^{-1}$ in $\mathrm{H}_{3} \mathrm{O}^{+}$ions necessary to assay $25 \mathrm{ml}$ of the potash in the presence of phenolphthalein.

The complete alkalimetric titer for its part is the volume of acid (expressed in ml) at $0.1 \mathrm{~mol}^{-L^{-1}}$ in $\mathrm{H}_{3} \mathrm{O}^{+}$ions necessary for assaying $25 \mathrm{ml}$ of potassium hydroxide in the presence of methyl orange (helianthine).

Aim: In the context of this manipulation, it is a question of firstly determining the concentration of carbonate ion $\left(\mathrm{CO}_{3}^{2-}\right)$ of the alkali solution and deducing from it the alkalimetric titre (TA). On the other hand, we determine the total alkalinity (full alkali titer, TAC) and the hydrogen carbonate ion concentration $\left(\mathrm{HCO}_{3}^{-}\right)$of the solution.

Principle: These measurements are based on the neutralization of free alkalis $\left(\mathrm{OH}^{-}\right)$carbonates and bicarbonates present in the sample by $\mathrm{H}_{2} \mathrm{SO}_{4}$, in the presence of colored. The change in phenolphthalein occurs as soon as the $\mathrm{pH}$ is 8.3. The reactions following are then complete:

$$
\begin{gathered}
\mathrm{HO}^{-}+\mathrm{H}_{3} \mathrm{O}^{+} \rightarrow 2 \mathrm{H}_{2} \mathrm{O} \\
\mathrm{CO}_{3}^{2-}+\mathrm{H}_{3} \mathrm{O}^{+} \rightarrow \mathrm{HCO}_{3}^{-}+\mathrm{H}_{2} \mathrm{O} \\
\mathrm{HCO}_{3}^{-}+\mathrm{H}_{3} \mathrm{O}^{+} \rightarrow \mathrm{CO}_{2}+\mathrm{H}_{2} \mathrm{O}
\end{gathered}
$$

The turn of helianthine on its part occurs when the $\mathrm{pH}$ is less than 4.5; that is to say, as soon as an excess of strong acid begins to appear.

$$
\begin{gathered}
\mathrm{HO}^{-}+\mathrm{H}_{3} \mathrm{O}^{+} \rightleftarrows 2 \mathrm{H}_{2} \mathrm{O} \\
\mathrm{CO}_{3}^{2-}+2 \mathrm{H}_{3} \mathrm{O}^{+} \rightleftarrows \mathrm{CO}_{2}+3 \mathrm{H}_{2} \mathrm{O} \\
\mathrm{HCO}_{3}^{-}+\mathrm{H}_{3} \mathrm{O}^{+} \rightleftarrows \mathrm{CO}_{2}+2 \mathrm{H}_{2} \mathrm{O}
\end{gathered}
$$

\subsection{Purification of Biogas from the Extracted Alkali}

For biogas purification we used the device shown on the corresponding page. The device is equipped with a plastic tube (PVC) one meter in length and $26 \mathrm{~mm}$ in diameter. 200 $\mathrm{ml}$ of the alkali solution at a concentration of $0.1 \mathrm{~g} / \mathrm{ml}$ are introduced into the tube. For the purification tests, the unit is calibrated at a low flow rate, the biogas inlet valve is opened in the tube containing the alkali solution and the purified biogas outlet valve. Every minute the time required for the detection of $\mathrm{CH}_{4}, \mathrm{CO}_{2}$ and $\mathrm{H}_{2} \mathrm{~S}$ by the analyzer is measured. The adsorption process is stopped as soon as the $\mathrm{CO}_{2}$ and $\mathrm{H}_{2} \mathrm{~S}$ concentrations of the gas at the outlet of the column are equal to those at the inlet. The absorption capacity of $\mathrm{CO}_{2}$ or $\mathrm{H}_{2} \mathrm{~S}$ is evaluated by the breakthrough curves of these gases.

\subsection{Dimensioning of the Decarbonation / Desulfurization Unit with an Alkali Solution}

Determining the amount of alkali $\left(\mathrm{K}_{2} \mathrm{CO}_{3}\right)$ to be prepared to remove $40 \%$ of the carbon dioxide $\left(\mathrm{CO}_{2}\right)$ contained in the biogas comes back from the neutralization reaction between the potash and the $\mathrm{CO}_{2}$ and from the balance of matter which in derives from calculating the number of moles and the desired mass.

\subsubsection{Padding Used}

The experimental determination of the porosity makes it possible to have an idea on the quantities of potash to be prepared, and subsequently the height of the column to be used. To achieve this, tests are carried out on a column of volume $V t$ in which there are plastic rachis rings for the packing and the water until observation of the displacement. The volume of the solution is measured and the volume of $V v$ is deduced thereafter. The calculation of the porosity is as follows: $\varepsilon=V v / V t$.

\subsubsection{Calculation of the Reaction Volume (Vr)}

Since the same plastic rings are used for the lamination of the large columns, the porosity is the same and considering the $V_{\text {solution }}$, the fixing of the height of the column taking into account the various parameters raised, allowed calculating the volume of the column $(\mathrm{Vt})$.

$$
V_{\text {solution }}=\frac{\pi \times D^{2} \times h}{4}
$$

\subsubsection{The amount of Alkali Required to Wash a Volume $V_{b}$ of Biogas}

For a good purification of the biogas, it is recommended to apply the $10 \%$ relation from which one takes a given quantity of the reagent according to the desired ratio and according to the size of the column used. The calculated reaction volume allows us to know the quantity of the purifying solution to be prepared necessary to eliminate the harmful elements of the biogas during a given time (ELA, 2015).

\subsubsection{Calculation of the Biogas Flow}

The speed of biogas flow imposes the height of the tube. Indeed, for the reactions of decarbonationdesulphurization take place, the constituents of the alkali solution $\left(\mathrm{K}_{2} \mathrm{CO}_{3}, \mathrm{Na}_{2} \mathrm{CO}_{3} \ldots\right)$ and the molecules of $\mathrm{CO}_{2}$ and $\mathrm{H}_{2} \mathrm{~S}$ of the biogas must meet for a given time and sufficient for saturation. The rate of flow of the biogas in the tube must then be limited.

$$
Q_{\text {biogas }}=\frac{v}{H} V_{a l k}
$$

With: $v=$ average volume $(\mathrm{cm} / \mathrm{min}) ; Q_{\text {biogas }}=$ flow of biogas.

\subsubsection{Calculation of the Residence Time}

Consider the steady-state tubular reactor of volume $V_{R}$ and 
$\mathrm{Q}_{\mathrm{o}}$ be the volume flow rate of the mixture in the reference state. The passage time is defined as the ratio of volume to volume flow:

$$
\tau=\frac{V_{R}}{Q_{o}}
$$

\subsubsection{Evaluation of the Performance of the Washing Column}

The performance evaluation is determined by the absorption capacity of the cartridge. The absorption capacity is obtained from the breakthrough curve. It is given by the following relationship:

$$
q_{\max }=\frac{F_{A i}}{V} \times d_{A i} \times t
$$

With: $\mathrm{q}_{\max }=$ absorption capacity $(\mathrm{ml} / \mathrm{l}) ; \quad V=$ volume of the solution; $d_{A i}=$ density of the species $\mathrm{Ai}\left(\mathrm{g} / \mathrm{cm}^{3}\right) ; \mathrm{F}_{\mathrm{Ai}}=$ Flow of $\mathrm{Ai}$ per unit of time $(\mathrm{mg} / \mathrm{min})$. $t=$ Time after which the concentration of $\mathrm{Al}$ at the exit of the column is equal to that at the inlet.

\subsection{Implementation of a Domestic Washing Column and Estimation of the Service Time of the Alkalis}

In this part, $\mathrm{CO}_{2}$ and $\mathrm{H}_{2} \mathrm{~S}$ are assimilated to perfect gases. The operating conditions are given for a $6 \mathrm{~m}^{3}$ digester normally fed and discharging at a constant pressure of 100 mbar. The performance evaluation is done for one liter of alkali solution.

\subsubsection{Dimensioning of Decarbonation Operations}

A-Calculation of the mass of $\mathrm{CO}_{2}$ absorbed by dm3 of the alkali solution.

The $\mathrm{CO}_{2}$ mass is given by the $\mathrm{CO}_{2}$ absorption capacity of 5-2-6.

$B$ - Calculation of the volume of $\mathrm{CO}_{2}$.

The volume of $\mathrm{CO}_{2}$ is obtained from the law of perfect gases. Which give:

$$
V_{\mathrm{CO} 2}=\frac{q_{\operatorname{maxCO} 2} \times R T}{P M_{\mathrm{CO} 2}} .
$$

$\operatorname{VCO} 2\left(\mathrm{~m}^{3}\right)$ volume of absorbed $\mathrm{CO}_{2} ; \mathrm{q}_{\max }=(\mathrm{g})$ equivalent $\mathrm{CO}_{2}$ mass $\mathrm{R}\left(\mathrm{JK}^{-1} \mathrm{~mol}^{-1}\right)=$ constants of perfect gases; $\mathrm{P}$ (mbar) $=$ operating pressure of the digester $\mathrm{T}(\mathrm{K})=$ absolute temperature.

C-Calculation of the corresponding biogas volume

Here, it is in the case where the biogas contains in proportion $40 \%$ of $\mathrm{CO}_{2}$ and $60 \%$ of $\mathrm{CH}_{4}$. The biogas volume is then given by: $V_{\text {biogas }}=\frac{V_{\mathrm{CO} 2}}{0,4}$

\subsubsection{Sizing of Desulfurization Operations \\ a. Material balance}

1) Reaction with iron oxide:

$$
\mathrm{Fe}_{2} \mathrm{CO}_{3}+3 \mathrm{H}_{2} \mathrm{~S} \rightarrow \mathrm{Fe}_{2} \mathrm{~S}_{3}+3 \mathrm{H}_{2} \mathrm{O}
$$

2) Reaction with sodium carbonate:

$$
\mathrm{Na}_{2} \mathrm{CO}_{3}+\mathrm{H}_{2} \mathrm{~S} \rightarrow \mathrm{Na}_{2} \mathrm{~S}+\mathrm{H}_{2} \mathrm{CO}_{3}
$$

b. Calculation of quantities

1) Calculation of the $\mathrm{H}_{2} \mathrm{~S}$ mass needed to react with iron oxide and $\mathrm{Na}_{2} \mathrm{CO}_{3}$.

$$
m_{\mathrm{H} 2 \mathrm{~S}}=\frac{3 m_{\mathrm{Fe}_{2} \mathrm{CO}_{3} \times M_{\mathrm{H}_{2} \mathrm{~S}}}}{M_{\mathrm{Fe} 2 \mathrm{CO} 3}}+\frac{m_{\mathrm{Na}_{2} \mathrm{CO}_{3}} \times M_{\mathrm{H} 2 \mathrm{~S}}}{M_{\mathrm{Na} 2 \mathrm{CO} 3}}
$$

2) Calculation of the volume of $\mathrm{H}_{2} \mathrm{~S}$ and biogas to be treated

The volume of $\mathrm{H}_{2} \mathrm{~S}$ is obtained from the ideal gas law [2022], and the volume of biogas is calculated by considering that the biogas contains at most $3 \%$ of $\mathrm{H}_{2} \mathrm{~S}$.

\subsubsection{Preparation of the Purifying Solution}

The purifying solution is obtained by taking a precise amount of the reagent and a given amount of the solvent. Once measured, the reagent is dissolved. Dissolution occurs for a period of 20 to 30 minutes.

\subsubsection{Parameters Followed}

Aim: In the context of this manipulation, it was a question of determining the alkalinity with a view to determining the quantity of carbon dioxide trapped in the soda.

Principle: These measurements are based on the neutralization of free alkalis (OH-), carbonates and bicarbonates present in the sample by $\mathrm{H}_{2} \mathrm{SO}_{4}$ in the presence of indicator colored. The change in phenolphthalein occurs as soon as the $\mathrm{pH}$ is 8.3. The following reactions are then complete:

$$
\begin{gathered}
2 \mathrm{~N}_{a}(\mathrm{OH})+\mathrm{H}_{2} \mathrm{SO}_{4} \rightarrow \mathrm{Na}_{2} \mathrm{SO}_{4}+2 \mathrm{H}_{2} \mathrm{O} \\
\mathrm{Na}_{2} \mathrm{CO}_{3}+\mathrm{H}_{2} \mathrm{SO}_{4} \rightarrow \mathrm{Na}_{2} \mathrm{SO}_{4}+\mathrm{H}_{2} \mathrm{CO}_{3} \\
2 \mathrm{~N}_{a}\left(\mathrm{HCO}_{3}\right)_{2}+\mathrm{H}_{2} \mathrm{SO}_{4} \rightarrow \mathrm{Na}_{2} \mathrm{SO}_{4}+2 \mathrm{H}_{2} \mathrm{CO}_{3}
\end{gathered}
$$

The turn of helianthine occurs as soon as the $\mathrm{pH}$ is less than 4.5; that is to say as soon as an excess of strong acid begins to appear [20].

\section{Results and Discussion}

\subsection{Characterization of Banana Stalks}

\section{A. Sample stem}

The chemical characteristics expressed as a percentage of the banana stalks used in this study are shown in Table 1 . In this table, the dry matter content varies from 80.1 to $92.58 \%$ of the samples dried at $105^{\circ} \mathrm{C}$ and $25^{\circ} \mathrm{C}$. ${ }^{\circ} \mathrm{C}$ are much higher than fresh samples $(11.3 \pm 0.14)$. This rise is due to the fact that the dry samples are almost free of their free water while the dry samples still have them. The organic matter content of sun-dried stalks varies from $83 \%$ to $79 \%$ respectively. The high levels of ash are obtained with the samples dried at $105^{\circ} \mathrm{C}(19.6 \%)$.

Table 1. Chemical characteristics of banana stalks.

\begin{tabular}{llll}
\hline \multirow{2}{*}{ Samples } & Percent & & \\
\cline { 2 - 4 } & Dry matter & Organic matter & Ash \\
\hline Fresh stems & $11.3 \pm 0.14$ & $69.46 \pm 1.01$ & $3.45 \pm 0.071$ \\
Sun-dried stems & $80.1 \pm 1.14$ & $83.83 \pm 0.3$ & $12.95 \pm 0.21$ \\
Oven dry bars & $92.58 \pm 1.21$ & $79.19 \pm 0.78$ & $19.6 \pm 0.2$ \\
\hline
\end{tabular}




\subsection{Sample Ash}

We present in Table 2 below the percentage of ash samples.

Table 2. Representation of ash samples.

\begin{tabular}{llll}
\hline & Dry matter & Organic matter & Ash content \\
\hline values & $94,5 \%$ & $0,03 \%$ & $99,6 \%$ \\
\hline
\end{tabular}

\subsection{Characterization of Alkali}

The $\mathrm{pH}$ of alkali extracted from banana stem ashes is 13.2. This result shows that the alkali solution is very basic. From this table, we find that the TA (0.0104) is lower compared to TAC (0.0153). This result actually confirms that the alkali we extracted is rich in dissolved salt. It is therefore rich in carbonate which is the most important element for the purification of biogas. We present in Figure 4 the Alkali extracted from the ashes of banana stalks (a) and those of the wood (b).
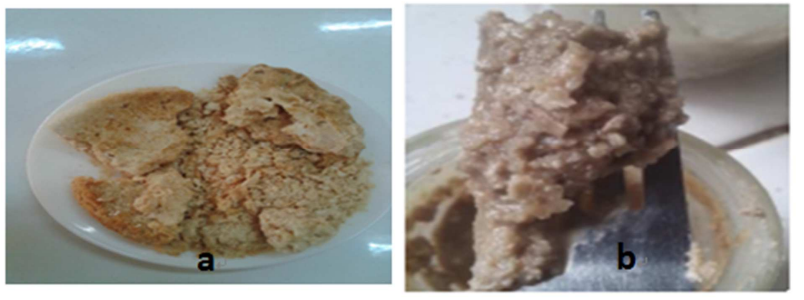

Figure 4. Alkali extracted ash from banana stalks (a) and wood ashes (b).

\subsection{Extraction Output}

In Table 3 below, we present the characteristics of the alkali extracted from banana stem ashes, and the ashes of meat and alkali burners.

Table 3. Alkali extraction yield.

\begin{tabular}{llllll}
\hline & & $\mathbf{W}_{\mathbf{C}}$ & $\mathbf{W}_{\mathbf{A}}$ & Non-alkali residue & Achievement of extraction of alkali in\% \\
\hline \multirow{2}{*}{ Ash from meat grills } & $1^{\text {st }}$ extraction & 1500 & 107,72 & 1389.06 & 7,18 \\
& $2^{\text {nd }}$ extraction & 1500 & 112.36 & 1386,15 & 7,51 \\
\multirow{2}{*}{ Ash of the banana stem. } & $1^{\text {st }}$ extraction & 700 & 91,65 & 608,35 & 13,09 \\
& $2^{\text {nd }}$ extraction & 700 & 92,31 & 607,69 & 13,19 \\
\hline
\end{tabular}

This table shows that the extraction efficiency of alkali from banana stem ashes is higher than that extracted from the ashes of meat grillers. This difference is justified by the fact that the banana stem is richer in mineral elements $(\mathrm{Na}, \mathrm{Mg}$, $\mathrm{K}, \mathrm{Ca}, \mathrm{Fe} . .$. etc.) and particularly in sodium according to the research conducted by [1].

\subsection{Evaluation of the Performance of the Column}

Table 4 below presents the basic data in the general washing conditions.

Table 4. General condition of washing.

\begin{tabular}{llll}
\hline General conditions of the washing & & \\
\hline Elements unavoidably present & $\mathbf{C H}_{\mathbf{4}}(\mathbf{V} \%)$ & $\mathbf{C O}_{2}(\mathbf{V} \%)$ & $\mathbf{H}_{2} \mathbf{S}$ \\
\hline Pressure in pascal & 9 & \\
Temperatures in ${ }^{\circ} \mathrm{C}$ & $4-7$ & \\
\hline
\end{tabular}

We specify here that the pressure condition is generally used for large purification structures more precisely on an industrial scale. The representation in Table 5 allows us to see the kinetic data of the biogas while Figure 5 shows the different parameters of the test procedure.

Table 5. Kinetic data.

\begin{tabular}{llll}
\hline Kinetic data & & & units \\
\hline Denomination & Symbol & values & $35-50$ \\
\hline Biogas speed & $\mathrm{V}$ & $\mathrm{Cm} / \mathrm{min}$ & 2,77 \\
Biogas flow & Qbiogas & $\mathrm{Cm}^{3} / \mathrm{min}$ & $20-30$ \\
Time of stays & $\tau$ & $\mathrm{min}$ & \\
\hline
\end{tabular}

Table 6. Parameter of the course of the tests.

\begin{tabular}{llll}
\hline Tests & Residence time (min) & Pressure (mbar) & Speed (cm / min) \\
\hline $1^{\text {st }}$ trials with tallow alkali. & 24 & 20 & 36 \\
$1^{\text {st }}$ test with wood alkali. & 12 & & \\
$1^{\text {st }}$ test with water. & 11 & 30 & 42 \\
$2^{\text {nd }}$ try with flag alkali. & 35 & & \\
$2^{\text {nd }}$ test with the alkali of the wood. & 35 & \\
$2^{\text {nd }}$ test with water. & 24 & \\
\hline
\end{tabular}

We have presented in this table the values of the different parameters from which the experiments were carried out.
These values have been chosen according to the experimental conditions of the laboratory and according to the volume of 
the purifying solution that the column can take.

\subsection{Decarbonation and Desulphurization of Biogas}

This is focused in the cases of Banana Stem Ash Alkali A- First wash

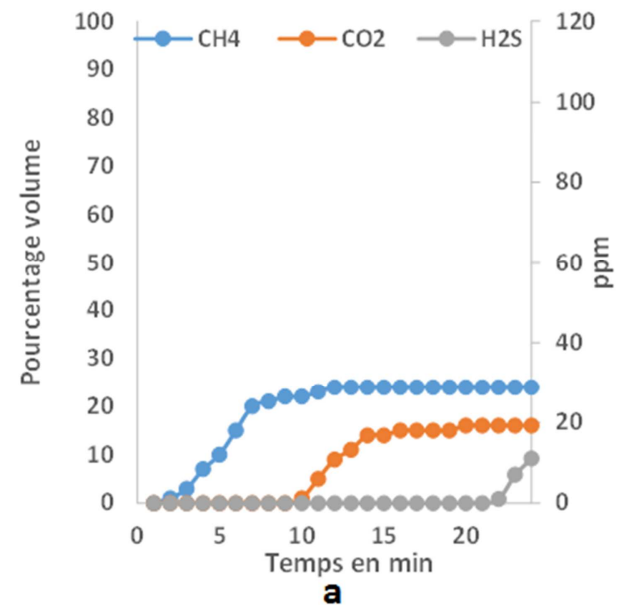

The $\mathrm{CO}_{2}$ and $\mathrm{H}_{2} \mathrm{~S}$ abatement rate at the first wash is represented by Figure 5 a (with banana stem ash alkali) and $b$ (the entry of the column).

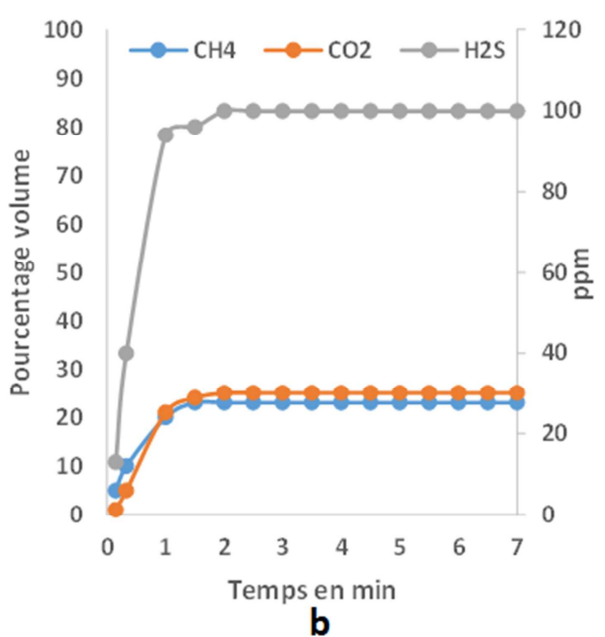

b

Figure 5. $\mathrm{CO}_{2}$ and $\mathrm{H}_{2} \mathrm{~S}$ abatement rate at first wash. a) with banana stem ash alkali, b) the entrance of the column.

The Figure 5 illustrates the evolution of the quantities of the main constituents of biogas $\left(\mathrm{CH}_{4}, \mathrm{CO}_{2}, \mathrm{H}_{2} \mathrm{~S}\right)$ recorded after each minute of washing (a) and every minute at the entrance of the column.

$B$ - Second wash

In this second phase of the biogas washing, we obtain different values depending on the case. All these values were taken under the same conditions of the washing (pressure and speed of the biogas).

Just like in the first wash, we notice that the time of appearance of the different constituents $\left(\mathrm{CO}_{2}, \mathrm{H}_{2} \mathrm{~S}\right)$ of the biogas varies according to whether it is treated with potash or with water. The values of Figures $6 \mathrm{a}$ and $\mathrm{b}$ are those taken at the inlet (before washing) of the biogas washing column. The Figures 5 shows that among the two constituents that we seek to eliminate, $\mathrm{CO}_{2}$ is the first to appear. It appears just after 8

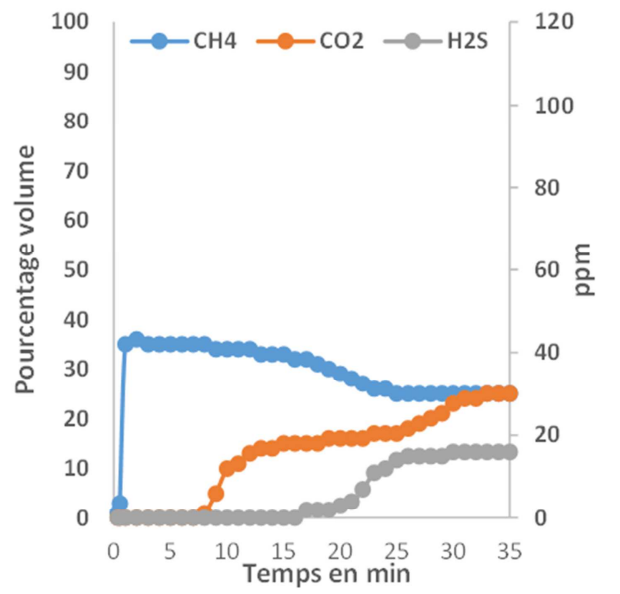

minutes of treatment, and whose molecules saturate completely from the $33^{\text {rd }}$ minute. On the other hand, the $\mathrm{H}_{2} \mathrm{~S}$ appears only after the $16^{\text {th }}$ minute and for its case it is only after the $31^{\text {st }}$ minute that all the molecules saturate. The saturation is observed when one notices the appearance of the constant values.

However, if we consider the treatment made from simple water, that is to say instead of potash we have simple water, we notice that the $\mathrm{CO}_{2}$ appears only a minute after the washing. We can thus realize that all the molecules begin to saturate after the first minute and all the molecules are saturated after the 4th minute of the washing of the biogas. Constant values are observed after this time. Thus, from all these differences, we already see the effect of potash on $\mathrm{CO}_{2}$ and $\mathrm{H}_{2} \mathrm{~S}$.

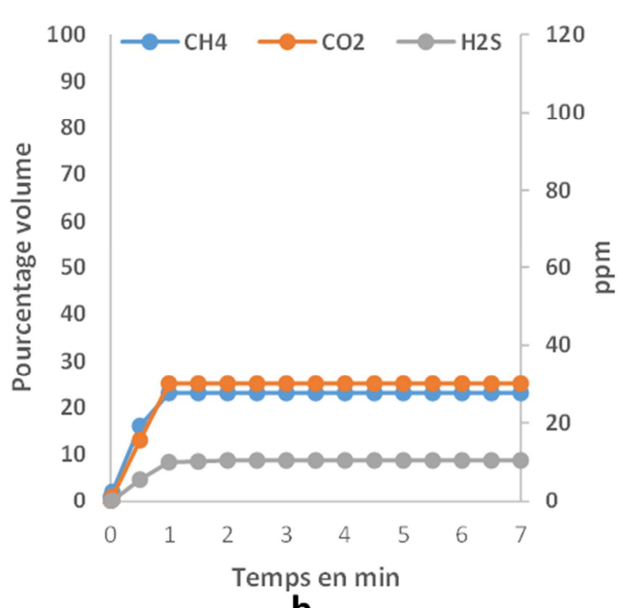

b

Figure 6. $\mathrm{CO}_{2}$ and $\mathrm{H}_{2} \mathrm{~S}$ abatement rate at the first wash. a with banana stem ash alkali, $b$ with water. 


\subsection{Summary Table of the Contents of All the Curves}

The Table 6 summarizes the values of saturation times and amounts of $\mathrm{CO}_{2}$ and $\mathrm{H}_{2} \mathrm{~S}$ shot during washing.

Table 7. Summary of values.

\begin{tabular}{|c|c|c|c|c|c|}
\hline & & $\begin{array}{l}\mathrm{CO}_{2} \text { saturation } \\
\text { time in minutes }\end{array}$ & $\begin{array}{l}\mathrm{H}_{2} \mathrm{~S} \text { saturation } \\
\text { time in minutes }\end{array}$ & $\begin{array}{l}\mathrm{CO}_{2} \text { absorption } \\
\text { capacity (in g) }\end{array}$ & $\begin{array}{l}\mathrm{H}_{2} \mathrm{~S} \text { absorption } \\
\text { capacity (in mg) }\end{array}$ \\
\hline \multirow{6}{*}{$\begin{array}{l}1^{\text {st }} \text { wash: pressure }=20 \mathrm{mbar} \\
\text { and speed }=36 \mathrm{~cm} / \mathrm{min} \\
2^{\text {nd }} \text { wash: pressure }=30 \mathrm{mbar} \\
\text { and speed }=200 \mathrm{~cm} / \mathrm{min}\end{array}$} & Wash with alkali solution of wood 1 & 7 & 0 & 3,16 & 14,32 \\
\hline & Washing with tallow alkali solution 1 & 10 & 22 & 4,52 & 20,45 \\
\hline & Washing with simple water 1 . & 2 & 6 & 2,95 & 9,588 \\
\hline & Wash with tallow alkali solution 2 . & 8 & 17 & 4,30 & 20,4 \\
\hline & Washing with simple water 2 & 1 & 2 & 0.56 & 2,77 \\
\hline & Wash with alkali solution of wood 2 . & 1 & 11 & 3,01 & 12,75 \\
\hline
\end{tabular}

The table above shows that for the first wash with alkali, the saturation time of potassium carbonates with $\mathrm{CO}_{2}$ is 10 minutes. The saturation time of the reactivity between the basic elements $\left(\mathrm{Na}_{2} \mathrm{CO}_{3}\right.$ and $\left.\mathrm{Fe}_{2} \mathrm{CO}_{3}\right)$ and $\mathrm{H}_{2} \mathrm{~S}$ is 22 minutes.

\subsection{Economic Analysis of the Costs and Benefits of the Purification Operation}

The biogas purification operation we are doing in this work has benefits that are undeniable in light of the current challenges of our planet. Indeed, the devastating economic consequences of climate change include:

a) the cost of repairs after disasters such as storms, floods and landslides;

b) the decline in factor productivity due to abnormally low rainy seasons and abnormally long dry seasons;

c) multiform agricultural losses. Direct economic losses to the world from extreme weather events have example jumped 250\% between 1998 and 2017 and reached USD 2,904 billion [23-26].

Thus, this operation could help to limit the emission of carbon dioxide into the atmosphere and consequently reduce the economic consequences caused by climate change.

Unlike the multiple benefits it generates, the purification operation has a virtually zero economic cost. Indeed, we have seen above that it mainly requires ash and banana stalk. Banana stalks and wood ash are waste products from the banana-plantain and firewood processes. We can not only get them for free but also participate in the fight against waste pollution in our cities and countryside. In addition, there is no other component that adds to the process of biogas purification if not time.

\section{Conclusion}

It was a question of purifying the biogas by column washing. A methodology based on several steps has been adopted. We first performed a functional analysis of the purification system. Then we extracted and characterized the alkalis. Finally, purification and sizing tests of the purification operations were carried out. These alkalis were extracted with an extraction yield of about $7 \%$ for meat grinder ash and an extraction yield of about $12 \%$ with ash from the banana stem. The washing of the biogas was carried out with an alkali concentration of $0.1 \mathrm{~g} / \mathrm{ml}$. The most favorable residence time and the best wash is 23 minutes for $\mathrm{CO}_{2}$ and 32 minutes for $\mathrm{H}_{2} \mathrm{~S}$. It is also noted that the most effective alkali for washing the biogas is that produced from the ash of the banana stem. During the wash test, a $\mathrm{CO}_{2}$ absorption capacity of $4.52 \mathrm{~g} / \mathrm{ml}$ of the alkali solution and $20.45 \mathrm{ppm} / \mathrm{ml}$ of $\mathrm{H}_{2} \mathrm{~S}$ was recorded. It follows that for these quantities of $\mathrm{CO}_{2}$ and $\mathrm{H}_{2} \mathrm{~S}$ absorbed per milliliter, during a domestic installation, for a volume of alkali of $1000 \mathrm{ml}$, we will have a volume of $\mathrm{CO}_{2}$ of $2.53 \mathrm{~m}^{3}$ and a volume of the biogas of $6.33 \mathrm{~m}^{3}$. An economic study of the operation is presented at the end of this study.

\section{Declaration of Competing Interest}

The authors declare they have no competing interests.

\section{Acknowledgements}

The authors will like to tanks the supervisors of chemical Engineering Laboratory of the University Institute of Technology for having permitted the conduction of experiments in their sites.

\section{References}

[1] Akindejoye F. Hammed T. B., Sridhar M. K. C., (2017). Potassium Recovery Potential of Selected Agroforestry and Organic Wastes in Ibadan, Nigeria. 12 pages.

[2] Ndzina Eyebe A, (2016). Production of Impregnated Ceramic Granules for the Desulphurization and decarbonation of biogas, 109 pages;

[3] Ela Mengue R. M. V, (2015). Implementation of a biogas purification unit andelectricity production in Lisey Mayo, village of cattle breeders, 101 pages.

[4] Babayemi J. O., Adewuyi G. O., Dauda K. T. Kayode A. A. A., (2011). The Ancient Alkali Production Technology and the Modern Improvement: A Review. Asian Journal of Applied Sciences, 4: 22-29, 5 pages.

[5] Ndlovu H., (2007). Ash from homestead fireplaces and wood as possible sources of minerals for livestock, 76 pages.

[6] Babayemi J. O., Dauda K. T., Nwude D. OKayode A. A. A., (2010). Evaluation of the composition and chemistry of the ash and the potash from various plant Materials-A Review. 6 pages. 
[7] Anneli P., Wellinger A., (2008). Biogas upgrading technologies - developments and innovations, 12 pages.

[8] Fraser V., (2008). Feasibility Study - Biogasupgrading and grid injection, 12 pages.

[9] Tou I., Igoud S., Touzi A. (2001), Production of Biomethane from the Feces animal, Rev. Energ. Ren.: Production et Valorisation - Biomasse, (2001) 103-108.

[10] Amahrouch A. (2010), Biogas, Renewable Energy Development Center (CDER), Kingdom of Morocco.

[11] Effebi K. R. (2009), Lagunage anaérobie: modeling combining primary settling and anaerobic degradation, $\mathrm{PhD}$ Thesis, Sciences and Environmental Management, University of Liège.

[12] Igoud S., Tou I., Kehal S., Mansouri N., Touzi A., (2002) First Approach to the Characterization of Biogas Produced from Cattle Drinking. Rev. Energ. Ren. 5: 123-128.

[13] Afilal M. E., Auriol M., Filali-Meknassi Y., (2007) Assessment of renewable energy sources in Morocco. In UNESCO, Renewable energies in Morocco - The debate is launched, Energie debiomasse, ISBN 9954-8068-2-2. 196 p.

[14] Ghaly A. E., Ramkumar D. R., Sadaks S. S., Rochon J. D., (2000) Effect of reseeding and $\mathrm{pH}$ controlon the performance of a two-stage mesophilic anaerobic digester operating on acidcheesewhey. Can. Agric. Eng. 42: 173-183.

[15] Eckenfelder W. W, Lawrence W. R, Lauria D. T. November (1956) Effect of various organic substances on oxygen absorption efficiency. Sewage and Industrial Wastes, 28 (11): $1357-1364$.

[16] Wheeler P., Jaatinen T., Lindberg A., Holm-Nielsen J. B., Wellinger A., Pettigrew A., (2000). Biogas upgrading and utilisation, DansTask 24: Energy from biological conversion of organic waste, IEA-Bioenergy,
[17] Meyer B., Heinzle E., january (1998). Dynamic determination of anaerobic acetate kinetics using membrane mass spectrometry, Biotechnology and Bioengineering, vol. 57, n2, p. $127-135$.

[18] Meynell P., (1976), Methane: Planning a Digester, Dorchester Prism Press, 150p.

[19] Coombs J., Meynell P. J., February (1982). Cleaning biogas, The Digest (newsletter of the BABA), vol. 10, p. 5-9.

[20] Lindberg A., Rasmuson S., (2006). Selective desorption of carbon dioxide from sewage sludge for in situ methane enrichment - part i: Pilot-plant experiments, Biotechnology and Bioengineering, vol. 95, no 5, p. 794-803.

[21] Lindberg A., Rasmuson S., (2007). Selective desorption of carbon dioxide from sewage sludge for in situ methane enrichment - part ii: modelling and evaluation of experiments, Biotechnology and Bioengineering, vol. 97, no 5, p. 10391052.

[22] O'keefe D. M., Brigmon R. L., Chynoweth D. P., (2000). Influence of methane enrichment by aeration of recirculated supernatant on microbial activities during anaerobic digestion », Bioresource Technology, vol. 71, no 3, p. 217-224.

[23] UNISDR, (2018), Economiclosses, poverty and disasters, Genève, Suisse, $31 \mathrm{p}$.

[24] Marniesse S., Ewa F., (2003), Lutte contre l'effet de serre, enjeux et débats, Agence Française de Développement, Paris, $127 \mathrm{p}$.

[25] GIEC, (2018), Conséquences d'un réchauffement planétaire de 1,5 o $C$, GIEC, Genève, Suisse.

[26] Problèmes Economiques, (2007), «Changement climatique, un défi mondial», no2930, pp 1-33. 